\title{
Técnicas de manipulação de tecido mole sobre implante dentário: Revisão de literatura
}

\author{
Soft tissue manipulation techniques on dental implants: Literature review
}

Técnicas de manipulación de tejidos blandos en implantes dentales: Revisión de literatura

\begin{abstract}
RESUMO
Introdução: O implante é considerado um procedimento previsivel e satisfatório. Entretanto, após sua instalação alguns defeitos em tecidos moles podem surgir, comprometendo a estética e a saúde dos tecidos peri-implantares. Dessa forma, variadas técnicas de enxertia de tecido mole são utilizadas como meio de reverter essas falhas. Objetivo: Analisar as principais técnicas cirúrgicas mucogengivais realizadas na região de implantes dentários. Método: 0 presente estudo foi elaborado através de revisão de literatura, utilizando livros e artigos científicos, disponíveis em língua portuguesa, inglesa e espanhola a partir do ano de 2015, obtidos através dos bancos de dados eletrônicos PubMed, SciELO, Lilacs e Google Acadêmico. Resultado: A revisão de literatura, demonstrou que é possível associar as cirurgias de enxerto de tecido mole nas reabilitações com implante dentário, reestabelecendo a harmonia e saúde gengival. Conclusão: Em casos de comprometimento das estruturas moles peri-implantares, o cirurgião dentista pode utilizar técnicas de cirúrgicas mucogengivais para a manutenção da saúde e estética dos tecidos peri-implantares.
\end{abstract}

DESCRITORES: Estética; Gengiva; Implante Dental

\section{ABSTRACT}

Introduction: The implant is considered a predictable and satisfactory procedure. However, after its installation, some soft tissue defects may appear, compromising the aesthetics and health of peri-implant tissues. Thus, various soft tissue grafting techniques are used as a means of reversing these failures. Objective: To analyze the main mucogingival surgical techniques performed in the region of dental implants. Method: This study was carried out through a literature review, using books and scientific articles, available in Portuguese, English and Spanish from 2015, obtained through the electronic databases PubMed, SciELO, Lilacs and Google Scholar. Result: The integrative review showed that it is possible to associate soft tissue graft surgeries in rehabilitation with dental implants, restoring harmony and gingival health. Conclusion: In cases of involvement of soft peri-implant structures, the dental surgeon can use mucogingival surgical techniques to maintain the health and aesthetics of peri-implant tissues.

DESCRIPTORS: Esthetic; Gums; Dental Implant.

\section{RESUMEN}

Introducción: El implante se considera un procedimiento predecible y satisfactorio. Sin embargo, después de su instalación, pueden aparecer algunos defectos en los tejidos blandos, comprometiendo la estética y la salud de los tejidos periimplantarios. Por tanto, se utilizan diversas técnicas de injerto de tejido blando como medio para revertir estos fallos. Objetivo: Analizar las principales técnicas quirúrgicas mucogingivales realizadas en la región de los implantes dentales. Método: Este estudio se llevó a cabo mediante una revisión de la literatura, utilizando libros y artículos científicos, disponibles en portugués, inglés y español a partir de 2015, obtenidos a través de las bases de datos electrónicas PubMed, SciELO, Lilacs y Google Scholar. Resultado: La revisión integradora demostró que es posible asociar cirugías de injerto de tejido blando en rehabilitación con implantes dentales, restableciendo la armonía y la salud gingival. Conclusión: En casos de afectación de estructuras periimplantarias blandas, el cirujano dental puede utilizar técnicas quirúrgicas mucogingivales para mantener la salud y estética de los tejidos periimplantarios. DESCRIPTORES: Estética; Encía; Implante dental.

RECEBIDO EM: 19/05/2021 APROVADO EM: 25/06/2021

\section{Débora Poliana Bernardo Ferreira}

Acadêmica de Odontologia pelo Centro Universitário UNIFASIPE.

ORCID: 0000-0002-4820-8009 
Ana Paula Bernardo Ferreira

Acadêmica de Odontologia pelo Centro Universitário UNIFASIPE.

ORCID: 0000-0002-4448-6626

Elizangela Fernanda Lauro

Acadêmica de Odontologia pelo Centro Universitário UNIFASIPE.

ORCID: 0000-0002-5921-4033

Maria Eduarda Tiburtino Silva

Acadêmica de Odontologia pelo Centro Universitário UNIFASIPE.

ORCID: 0000-0001-7441-1724

\section{Fabrício Rutz da Silva}

Cirurgião-Dentista. Mestre em odontologia em Saúde coletiva e Doutor em clínica odontológica, área de endodontia, ambos pelo FOP/UNICAMP. Coordenador do curso de Odontologia do Centro Universitário UNIFASIPE.

ORCID: 0000-0001-6728-6689

\section{Giuliene Nunes de Sousa Passoni}

Cirurgiã-Dentista. Professora Mestre orientadora Titular da disciplina de Periodontia Il e de Implantodontia do curso de odontologia do Centro Universitário UNIFASIPE.

ORCID: 0000-0002-6900-3950

\section{INTRODUÇÃO}

A utilização de implante dental e implantes colocados imediatamente após a extração dentária é considerada como tratamento previsível, contudo podem ocorrer alterações significativas em tecido mole comprometendo os resultados clínicos. A agressão gerada nessa região, propicia a recessão gengival, ocasionando comprometimento estético da reabilitação. Dessa maneira, estudos vêm sendo conduzidos em busca de técnicas de manutenção da qualidade da mucosa peri-implantar e alternativas de melhorarias de suas propriedades $1,2,3$.

Para solucionar defeitos em tecidos moles provenientes de implantes dentais, foram desenvolvidas variadas técnicas de manejo de tecido mole. Para obter um melhor resultado estético é preciso identificar qual a melhor terapia a ser adotada, observando as características, vantagens e indicação de técnica para cada caso clínico ${ }^{4}$.

$\mathrm{O}$ manejo adequado dos tecidos gengivais na região peri-implantar é um dos fatores contribuintes para a melhora dos resultados estéticos. Entretanto, se não bem conduzido pode ocasionar danos, como a recessão gengival e a reabsorção óssea. Diversas causas podem estar associadas ao insucesso da reparação do tecido mole em volta do implante, como qualidade da crista óssea vestibular, tipo de implante utilizado, distância entre o implante e a tábua óssea, peri-implantite e mucosite peri-implantar ${ }^{1,2,5}$.

Assim, com a utilização de técnicas de manuseio da mucosa é possível melhorar o espessamento do tecido mole e aumentar a quantidade de mucosa ceratinizada, através de enxertos autógenos de tecidos moles e substitutos de tecidos, que foram pensados para reduzir o risco de recessóes gengivais, manter a estabilidade do nível da mucosa ceratinizada e compensar possíveis alterações pós-cirúrgicas ${ }^{1,2,6}$.

Dentre as mais variadas técnicas de manipulação tecidual mole, está a técnica de cirurgia de enxerto com tecido conjuntivo, considerada padrão ouro, pois oferece boa estética e recobrimento satisfatório se bem realizada. A técnica conta com o benefício de melhoria da cicatrização e aumento na espessura da mucosa ceratinizada ${ }^{6}$.

Além disso, pacientes impossibilitados de realizar cirurgias de enxerto de tecido conjuntivo, podem contar com outras técnicas reparadoras, como no caso de cirurgia de enxerto de tecido gengival livre ou uso de materiais alógenos como no caso da matriz dérmica acelular ${ }^{3,4,5,6}$.

Os defeitos em estruturas moles após implante dentário, não são raros e acabam comprometendo o sucesso do tratamento.
Dessa forma, o presente estudo tem por objetivo analisar as principais técnicas cirúrgicas mucogengivais realizadas na região de implantes dentários, através de revisão de literatura, visando demonstrar técnicas reparadoras, reestabelecendo a harmonia e saúde gengival ${ }^{1}$.

\section{MÉTODO}

Este estudo foi elaborado através de revisão bibliográfica, com dados obtidos através de livros, com o tema implantodontia e periodontia, e mediante a consulta de publicações disponíveis em bases eletrônicas como National Library of Medicine (PubMed), Scientific Electronic Library Online (SciELO), Literatura Latino-Americana e do Caribe em Ciência da Saúde (LILACS) e Google Acadêmico.

A seleção das bibliografias utilizadas se deu através das recomendações do instrumento PRISMA, que foi realizada a partir de uma triagem de leitura dos títulos, resumos e descritores, extração dos artigos disponíveis para download para leitura integral, analise crítica dos estudos e interpretação das evidencias científicas para a revisão.

Foi realizado recorte temporal entre 2015-2020 e incluídos artigos em língua inglesa, portuguesa e espanhola. E foram 


\section{artigo}

Ferreira, D.P.B.; Ferreira, A.P.B.; Lauro, E.F.; Tiburtino Silva, M.E.; Rutz da Silva, F.; Passoni, G.N.S.

Técnicas de manipulação de tecido mole sobre implante dentário: Revisão de literatura

utilizados os seguintes descritores "Implante dental". Gengiva. Estética.

Foram inclusos artigos originais (de delineamento experimental ou observacional), monografias, capítulos de livros, e artigos de revisão disponíveis na íntegra, nos últimos 5 anos, que contemplasse a pergunta norteadora e excluídos artigos que não respondessem ao objetivo da pesquisa.

\section{RESULTADOS}

\section{Figura 1- Fluxograma da pesquisa bibliográfica}

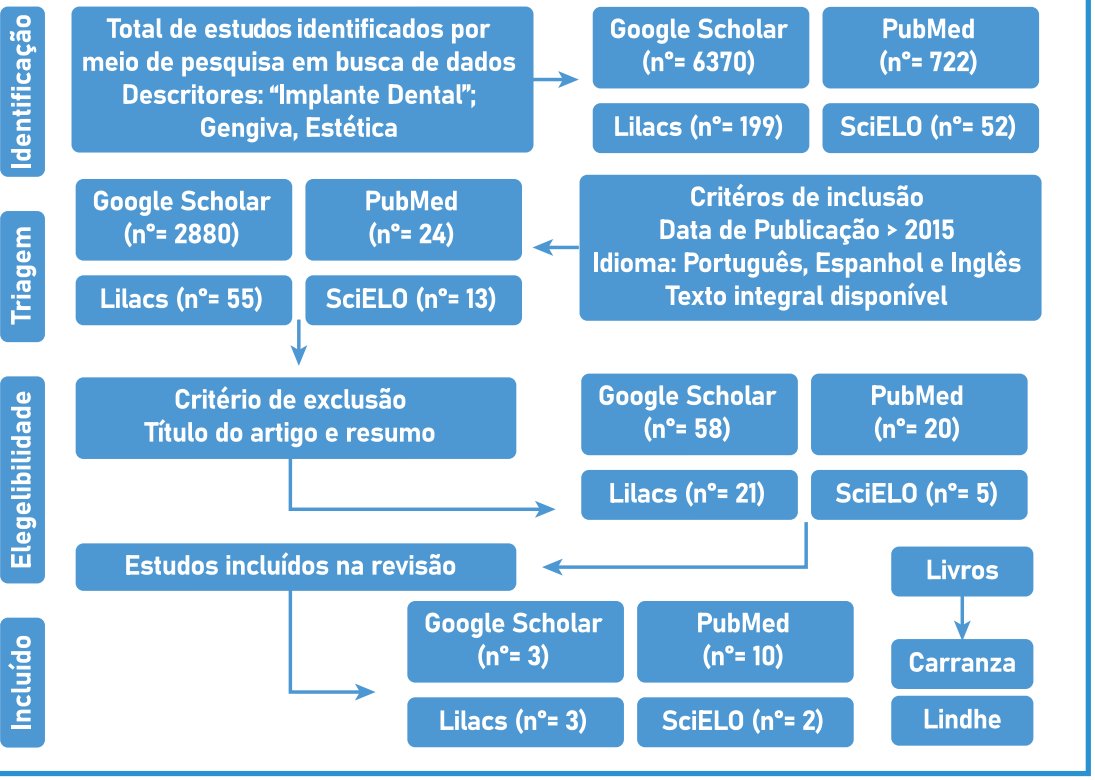

Fonte: Autoria própria
Esta pesquisa visou verificar na literatura os diferentes métodos de manipulação de tecido mole sobre implante dentário. Através da revisão integrativa, foi possível obter mais de 7 mil estudos, que foram filtrados e analisados para inclusão nessa pesquisa.

Ao inserir os diferentes descritores nas bases de buscas selecionadas e aplicar os critérios de inclusão idioma da pesquisa, data e texto integral disponível obteve-se
2.972 resultados. Destes, foram aplicados os critérios de exclusão, onde foram lidos os títulos e resumos, os considerados irrelevantes à pesquisa foram excluídos, restando 94 estudos. Após meticulosa leitura dos 94 artigos, apenas 20 foram inclusos nessa pesquisa devido similaridade com o objetivo dessa pesquisa.

\section{DISCUSSÃO}

Importância da presença da mucosa ceratinizada para o sucesso do implante dentário

A anatomia da gengiva é composta por uma camada epitelial e tecido conjuntivo subjacente conhecido como lâmina própria, que juntos circundam os dentes, originando a gengiva marginal livre, gengiva inserida e gengiva interdental ou papilar. Quando em estado saudável, apresentam como característica coloração rosa claro e em pessoas negras coloração acastanhada, textura pontilhada chamadas de "stippling” que se assemelha a casca de laranja, com espessura variante entre 1 a $9 \mathrm{~mm}$. Entretanto, esse tecido mole pode sofrer alterações quando circunda um implante dentário, desencadeando problemas que comprometem a estética e saúde periodontal do paciente ${ }^{1,2,3}$.

$\mathrm{O}$ tecido mole que circunda o implante dentário é chamado de mucosa

Quadro 1- Síntese das pesquisas bibliográficas inseridas na revisão integrativa, de acordo com o número de referência, ano de publicação, título da obra, objetivo da pesquisa bibliográfica e metodologia utilizada.

QUADRO 1: SIINTESE DAS BIBLIOGRAFIAS ENCONTRADAS NAS BASES DE DADOS

\begin{tabular}{|c|c|c|c|c|}
\hline $\mathrm{N}^{\circ}$ & ANO & TÍTULO & OBJETIVO & $\begin{array}{l}\text { DELINEAMENTO } \\
\text { METODOLÔGICO }\end{array}$ \\
\hline 1 & 2015 & $\begin{array}{c}\text { Concomitant Correction of a Soft-Tissue Fenes- } \\
\text { tration with Keratinised Tissue Augmentation By } \\
\text { Using A Rotated DoublePedicle Flap During Secon- } \\
\text { d-Stage Implant Surgery- A Case Report }\end{array}$ & $\begin{array}{l}\text { Realizar a correção de uma fenestração de } \\
\text { tecido mole com aumento de tecido que- } \\
\text { ratinizado usando um retalho de pedículo } \\
\text { duplo girado durante a cirurgia de implante }\end{array}$ & $\begin{array}{l}\text { Foi realizado um } \\
\text { relato de caso }\end{array}$ \\
\hline 4 & 2015 & $\begin{array}{l}\text { Enxerto de tecido mole como opção para suprir } \\
\text { defeitos peri-implantares }\end{array}$ & $\begin{array}{l}\text { Demonstrar o sucesso de uma das técnicas } \\
\text { cirúrgicas plásticas periodontais como } \\
\text { alternativa de recobrimento de áreas que } \\
\text { possam desfavorecer a estética vermelha }\end{array}$ & $\begin{array}{l}\text { Conduziu-se pesquisa } \\
\text { através de relato de } \\
\text { caso clínico }\end{array}$ \\
\hline 18 & 2018 & $\begin{array}{l}\text { O uso de matrizes dérmicas no tratamento de } \\
\text { recessões gengivais }\end{array}$ & $\begin{array}{l}\text { Apresentar um relato de caso clínico onde } \\
\text { se utilizou do enxerto de matriz dérmica } \\
\text { acelular para recobrimento radicular }\end{array}$ & Relato de caso Clínico \\
\hline & & & & \\
\hline
\end{tabular}


peri-implantar, e possui várias propriedades semelhantes à da gengiva envolta aos dentes naturais, porém exibe a ausência do ligamento periodontal. A característica da mucosa peri-implantar será definida durante o processo de cicatrização da ferida, depois da instalação do implante dental. A recuperação correta, irá proporcionar a adesão do tecido mucoso ao implante, impedindo que produtos e microrganismos provenientes da cavidade oral tenham acesso ao tecido ósseo, auxiliando na correta osseointegração $7,8,9,10$.

Uma largura mínima da mucosa ceratinizada está correlacionada à saúde gengival. Estudos indicam que $80 \%$ de gengivas com mais de $2 \mathrm{~mm}$ de mucosa ceratinizada apresentavam-se saudáveis enquanto que as superfícies com menos de $2 \mathrm{~mm}$ de $\mathrm{mu}-$ cosa ceratinizada estavam inflamadas 8 . Foi concluído que para manter a saúde dos tecidos moles, era necessário ter no mínimo $2 \mathrm{~mm}$ de mucosa ceratinizada. Além disso, estudos demonstraram que em pacientes com implante dental que possuíam menos que $2 \mathrm{~mm}$ de mucosa ceratinizada apresentavam maior desconforto durante a escovação, maior acúmulo de placa e inflamação peri-implantar ${ }^{8,11}$.

Para obter a saúde e uma boa aparência do implante, estudos indicam que é fundamental ter a presença da mucosa ceratiniza$\mathrm{da}$, que consiste num tecido conjuntivo denso e rico em colágeno delineado por epitélio queratinizado. Para o tratamento ser bem-sucedido, é necessário interligar o implante a saúde dos tecidos peri-implantares. Além disso, a pesquisa demonstrou que em regiões implantadas com uma fina área de mucosa prejudicou o processo de cicatrização e induziu a reabsorção óssea marginal $7,9,11$.

Embora no passado houvesse a crença de que a mucosa ceratinizada não tinha relação com o sucesso do implante dental. Estudos mais recentes trazem a presença dessa mucosa como fator importante para o sucesso dos implantes osseointegrados. A ausência de mucosa ceratinizada peri-implantar pode estar associada ao aumento do acúmulo de placa bacteriana, perda de inserção e recessão da mucosa peri-implantar. Pacientes portadores de implan- tes sem a presença de mucosa ceratinizada relataram sofrer com dores e desconfortos. Onde tais sintomas foram amenizados quando realizado enxerto de tecido mole no local ${ }^{10,12,13}$.

$\mathrm{O}$ recobrimento gengival insatisfatório em torno dos implantes dentários gera um acúmulo de placa bacteriana nessa região, favorecendo no desenvolvimento de uma resposta inflamatória, especialmente em implantes com superfície rugosa ${ }^{12,13}$.

\section{Enxerto de tecido conjuntivo}

O implante dental é uma alternativa para o tratamento reabilitador em pacientes edêntulos, possibilitando a restituição das funções mastigatórias, fonéticas e estéticas. Para que a terapia seja eficaz, alguns fatores são importantes como qualidade e quantidade de tecido ósseo, adequada saúde geral, boa higiene bucal, estabilidade nos implantes, ausência de hábitos parafuncionais, e também a presença de tecido mole envolta ao implante ${ }^{4,14}$.

Embora fundamental para a estética e saúde bucal, o tecido mole nem sempre está presente, em quantidade e qualidade satisfatórias, levando a indicação de enxertos no momento da instalação do implante ou após. A enxertia de tecido mole, é uma técnica idealizada para promover a melhoria da cicatrização e aumentar a espessura da mucosa ceratinizada. Ensaios clínicos randomizados, demonstraram que a utilização do enxerto de tecido conjuntivo aumentou a espessura gengival na região do implante dental em comparação com implantes sem a utilização de enxerto de tecido conjuntivo ${ }^{6,7}$.
O uso de enxertos autógenos, proporcionam uma aparência mais natural aos tecidos moles, por essa característica e por oferecer resultados previsíveis e consistentes o enxerto de tecido conjuntivo está sendo cada vez mais indicado, melhorando o espessamento dos tecidos moles, sendo utilizado no tratamento de recessão, aumento e reconstrução de papilas ${ }^{14,15}$.

$\mathrm{O}$ enxerto de tecido conjuntivo é realizado utilizando tecido mole subepitelial, com área doadora podendo ser a região de palato e coxim retromolar, utilizando uma abordagem de "porta alçapão". Em relação ao enxerto epitelizado, a técnica de enxerto conjuntivo se mostra superior, pois apresenta um melhor resultado estético e a região doadora é mais preservada ${ }^{6,7}$.

A enxertia com tecido conjuntivo é amplamente utilizada para correção de defeitos de tecidos moles peri-implantar, sendo considerada um método confiável. Essa cirurgia corretiva, apresenta como vantagem o recontorno da margem peri-implantar e aumento do volume bucal do tecido mole peri-implantado, e manifesta vantagens quanto a técnica que utiliza MDA, que é mais suscetível a complicações clínicas como colonização e infecção bacteriana ${ }^{5,16}$.

A utilização de enxertos conjuntivos demonstrou prevenir complicações que possam surgir pelo uso de membranas sintéticas, além de melhorar o metabolismo no local dos tecidos superficiais e aumentou a altura e espessura do tecido. Dessa forma, a técnica se mostra promissora em casos onde o paciente manifesta tecido mole insuficiente ou biotipo gengival fino, permitindo a transformação da mucosa
Figura 2 - A direita imagem de retração da mucosa peri-implantar, centralizado a cobertura da recessão com enxerto de tecido conjuntivo e à esquerda cobertura bem-sucedida após 1 ano de cirurgia
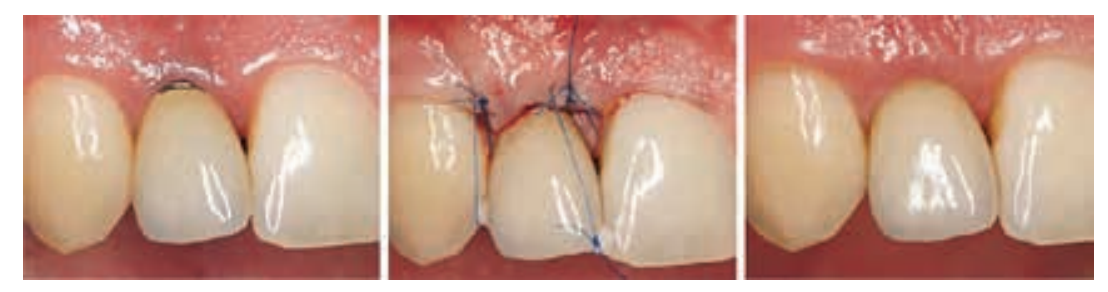

Fonte: FICKL 12 
fina em espessa e ocultando os materiais restauradores do implante ${ }^{16}$.

\section{Enxerto gengival livre}

Devido à frequência na observação de defeitos em tecidos moles em torno dos implantes, a utilização de técnicas cirúrgicas reparadoras como a cirurgia mucogengival peri-implantar vem sendo cada vez mais realizada, com o objetivo melhorar o tecido mole e devolver a harmonia das estruturas gengivais $1,2,17$.

A presença da gengiva ceratinizada, é vastamente correlacionada com a melhoria da saúde dos tecidos moles, entretanto quando o paciente apresenta quantidade insuficiente de tecido mole ceratinizado o CD pode utilizar a técnica de enxerto gengival livre, que apresenta boa previsibilidade e fácil execução ${ }^{1,2,17}$.

$\mathrm{O}$ enxerto com tecido gengival livre é descrito como previsível e popular na correção de defeitos em tecido mole, auxiliando no aumento de largura do tecido ceratinizado. Todavia, a técnica apresenta algumas desvantagens, como desconforto e dor pós-operatória, limitada disponibilidade e quantidade de área doadora e morbidade do paciente ${ }^{15}$.

A cirurgia de enxerto gengival livre pode ser indicada em diferentes tempos cirúrgicos, podendo ser antes da instalação dos implantes dentários, durante a cirurgia de colocação dos implantes dentários ou após a colocação do implante dental. Essa técnica atua auxiliando no aumento de largura do tecido ceratinizado. $\mathrm{O}$ enxerto, pode ser realizado sob anestesia local, tendo como área doadora o palato, onde será extraída uma fina camada de tecido ${ }^{13,15}$.
Diferentes casos podem sugerir a necessidade da enxertia, dentre elas está a recessão gengival com perda contínua de inserção, o que diminui a quantidade de gengiva ceratinizada podendo levar ao uso da técnica reparadora com enxeria de tecido gengival livre ${ }^{1,17}$.

\section{O enxerto com}

tecido gengival livre

é descrito como

previsível e popular

na correção de

defeitos em tecido

mole, auxiliando no

aumento de largura do

tecido ceratinizado.

Além disso, o profissional pode utilizar a técnica de enxerto gengival livre misto, onde serão utilizados o enxerto gengival livre com pedículo de tecido conjuntivo. Essa técnica visa condicionar o tecido gengival previamente à cirurgia reconstrutiva.

A enxertia mista oferece um bom aumento gengival em altura e espessura e se mostrou uma excelente opção para pacientes com mucosa ceratinizada insuficiente.

Figura 3 - A direita área de incisão para remoção de parte doadora para enxerto gengival livre misto, ao meio adaptação e sutura do enxerto gengival livre misto no leito receptor e à esquerda cicatrização após 40 dias da cirurgia
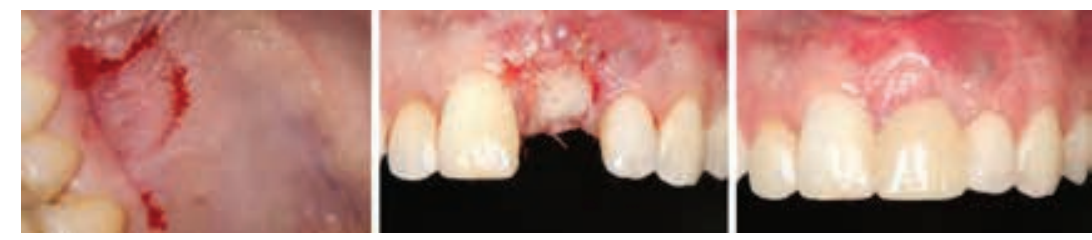

Fonte: RIBEIRO, et al. ${ }^{17}$
Embora a cirurgia com enxerto autógeno cause maior desconforto pós-cirúrgico e maior tempo operatório, os benefícios são superiores e é considerada técnica padrão-ouro com maior satisfação do paciente e melhor estética ${ }^{17}$.

\section{Matriz dérmica acelular (MDA)}

Apesar dos resultados dos enxertos com tecido conjuntivo serem satisfatórios, a disponibilidade dessa técnica é limitada, devido a quantidade restrita de áreas doadoras. Como alternativa para substituição desse tratamento, são utilizados enxertos com MDA, o que possibilita o reparo tecidual, mesmo em casos em que o paciente não dispõe de áreas doadoras para enxertia autógena ${ }^{6,18}$.

A MDA, trata-se de um biomaterial extraído da derme de cadáveres humanos, que passa por um processo de exclusão celular, passando por vários procedimentos que irão remover possíveis fatores que levem a rejeição do tecido. Constituída por dois lados: um o tecido conjuntivo e outro a membrana basal, a MDA possui também a vantagem de manutenção da coloração compatível com a dos tecidos adjacentes $15,18,19,20$.

A MDA age como um molde para regeneração tecidual. Após o transplante da derme acelular ela cria um espaço vazio que induz a ocupação de fibroblastos e outras células do paciente. Ocorre então uma invasão dessas células, que se proliferam em direção ao tecido, transformando a matriz dérmica acelular em novas fibras de colágeno ${ }^{18,19,20}$.

A sua revascularização ocorre entre 1 semana, já a sua remodelação leva entre 3 a 4 meses para ocorrer completamente. Em resultados de estudos randomizados, o material se mostrou promissor, alcançando $86 \%$ de regeneração tecidual da área implantada ${ }^{17,18}$.

Estudos comparativos entre enxerto com tecido conjuntivo e MDA, demonstraram não haver diferenças significativas entre as duas técnicas. Em uma pesquisa, onde foram analisados 107 defeitos durante um período de 12 meses, resultados semelhantes entre enxerto de tecido conjuntivo e MDA foram encontrados, sendo obtido um recobrimento de $96,2 \%$ com 
tecido conjuntivo subepitelial e 95,8\% com MDA, demonstrando que ambas as técnicas obtiveram resultados satisfatórios para correção de defeitos em tecidos moles ${ }^{15,17}$.

Apesar de a MDA ser mais utilizado em casos de impossibilidade de se obter uma área doadora, ela possui alguns benefícios em relação ao enxerto com tecido autógeno. Algumas das possíveis vantagens são: redução do tempo cirúrgico, redução dos sítios cirúrgicos, quantidade ilimitada de material doador disponível, redução da dor e desconforto pós-operatório. Entre- tanto, a MDA não possui a mesma capacidade de revascularização que os enxertos autógenos, apresentando, dessa forma, limitações na sua indicação ${ }^{15,18}$.

\section{CONCLUSÃO}

Com base nos artigos e livros pesquisados é possível concluir que os defeitos nos tecidos peri-implantares não são raros, e que diferentes técnicas podem ser utilizadas para sua correção, cabendo ao profissional avaliar qual a mais indicada de acordo com as necessidades do paciente. Além disso, constatou-se que a presença da mucosa ceratinizada é de suma importância para o sucesso do tratamento, proporcionando maior conforto e melhora da estética da região peri-implantar. Todavia, em pacientes com ausência ou quantidade insuficiente desse tecido, pode ser realizado a técnica de enxerto de tecido gengival livre e em casos de impossibilidade de obter áreas doadoras pode-se lançar mão de técnicas de enxerto com tecidos alógenos, como no caso da matriz dérmica acelular.

\section{REFERÊNCIAS}

1. Reddy AA, Kumar PA, Sailaja S, Chakravarthy Y, Chandra RV. Concomitant Correction of a Soft-Tissue Fenestration with Keratinised Tissue Augmentation By Using A Rotated Double-Pedicle Flap During Second-Stage Implant Surgery- A Case Report. J Clin Diagn Res. 2015; 9(12): 16-9.

2. Garabetyan J, Malet J, Kerner S, Detzen L, Carra MC. The relationship between dental implant papilla and dental implant mucosa around single tooth implant in the esthetic area: A retrospective study. Ver. Clin Oral Impl Res. 2019; 9(12): 1-9.

3. Lee CT, Sanz-Miralles E, Zhu L, Glick J, Heath A, Stoupel J. Predicting bone and soft tissue alterations of immediate implant sites in the esthetic zone using clinical parameters. Clin Implant Dent Relat Res. 2020; 22(3): 325-32.

4. Serrilho RP, Tolentino LS, Pinto GNS. Enxerto de tecido mole como opção para suprir defeitos peri-implantares. Relato de caso clínico. Rev Assoc Paul Cir Dent 2015; 69(4):350-4.

5. Deliberador TM, Vieira JZ, Bonacin R, Storrer CLM, Santos FR, Giovanini AF. Soft tissue changes after connective tissue grafts around immediately placed and restored dental implants in the esthetic zone: A systematic review and meta-analysis. Quintessence International 2015; 46(2): 139-44.

6. Momen AA, Nabeel A. Soft tissue changes after connective tissue grafts around immediately placed and restored dental implants in the esthetic zone: A systematic review and meta-analysis. Wiley J Esthet Restor Dent. 2019; 32(3): 1-11.

7. Lindhe J, Lang NP, Karring T. Tratado de periodontia clínica e implantologia oral. 5. ed. Rio de Janeiro: Guanabara; 2010.

8. Berridge JP, Johnson TM, Erley KJ, Hill RB, Lane JD, Schlam KK, Dunham DD, Miller Jr PD. Focus on epithelialized palatal grafts. Part 2: Development of the implant site. Clinical Advances in Periodontics 2019; 9(3): 147-56.

9. Silva PRA. A importância da gengiva ceratinizada na implantodontia: revisão de literatura [monografia]. Londrina: Universidade Estadual de Londrina - UEL; 2017.

10. Carranza FA, Newman MG, Takei HH, Klokkevold PR. Carranza Periodontia Clínica. 11. ed. Rio de Janeiro: Elsevier; 2012.
11. Patrício TA. A Importância da Banda de Mucosa Queratinizada Superior a 2 mm na Taxa de Sucesso e Sobrevivência dos Implantes [mestrado]. Integrado em Medicina Dentária Faculdade de Medicina da Universidade de Coimbra - UC; 2018.

12. Fickl S. Recession of the peri-implant mucosa: clinical significance and therapeutic opportunities. Quintessence International 2015; 46(8): 671-6.

13. Pazmino VFC, Sánchez MDPR, Maciel J,Almeida JM, Bassi APF. Aumento da mucosa queratinizada em área peri-implantar com enxerto gengival livre. PerioNews 2015; 9(6): 550-4.

14. Bienz SP, Jung RE, Sapata VM, Hämmerle CHF, Hüsler J, Thoma DS. Volumetric changes and peri-implant health at implant sites with or without soft tissue grafting in the esthetic zone, a retrospective case-control study with a 5 -year follow-up. Clin Oral Implants Res. 2017; 28(11): 1459-65.

15. Santos DG. A utilização dos fatores de crescimento e biomateriais na regeneração dos tecidos moles: uma revisão de literatura [monografia]. Belo Horizonte: Universidade Federal de Minas Gerais - UFMG; 2017.

16. Rojo R, Frutos JC, Manchón A, Molinera JR, Sammartino G, Guirado LC, Gómez R Techniques for increasing soft tissue in implants placed and provisionally immediately: a systematic review. Journal BioMed Research International. 2016; (4): 1-12.

17. Ribeiro A, Freire JCP, Barreto JO, Ribeira ED, Lira-Jr R, Menezes DJB. Enxerto gengival livre para correção de defeitos de tecido mole previamente a cirurgias reconstrutivas. Arch Health Invest. 2020; 9(2):150-4.

18. Silva JM. O uso de matrizes dérmicas no tratamento de recessões gengivais: Uma Revisão De Literatura [monografia]. São Cristóvão. Universidade Federal de Sergipe - UFS; 2018.

19. Quesada JG. Recubrimiento radicular de recesiones gingivales con matriz dérmica acelular. Reporte de un caso clínico. ODOVTOS-International Journal of Dental Sciences 2016; (18): 69-75.

20. Nolasco PMP. Aumento de tecidos moles peri-implantares com banda de enxerto gengival livre e matriz de colágeno xenógena [mestrado]. Integrado em Medicina Dentária Faculdade de Medicina da Universidade de Coimbra - UC; 2017. 